\title{
The uniquely human in human nature
}

\section{Citation}

Kagan, Jerome. 2004. “The Uniquely Human in Human Nature." Daedalus 133 (4) (September):

77-88. doi:10.1162/0011526042365609. http://dx.doi.org/10.1162/0011526042365609.

\section{Published Version}

doi:10.1162/0011526042365609

\section{Permanent link}

http://nrs.harvard.edu/urn-3:HUL.InstRepos:25283809

\section{Terms of Use}

This article was downloaded from Harvard University's DASH repository, and is made available under the terms and conditions applicable to Other Posted Material, as set forth at http:// nrs.harvard.edu/urn-3:HUL.InstRepos:dash.current.terms-of-use\#LAA

\section{Share Your Story}

The Harvard community has made this article openly available.

Please share how this access benefits you. Submit a story.

Accessibility 


\section{Jerome Kagan}

\section{The uniquely human in human nature}

We features, as manufacturers do when they provide a description of the parts of an assembly-required crib; or by comparing the object with one from a related category, as parents do when they tell their child that a zebra has stripes but a horse does not. Most answers to the question What is human nature? adopt this second strategy when they nominate the features that are either uniquely human or that are quantitative enhancements on the properties of apes. I adopt

Jerome Kagan, a Fellow of the American Academy since 1968 and chair of the Academy's Committee on Publications and Public Relations, is Daniel and Amy Starch Research Professor of Psychology and former codirector of the MindBrain-Behavior Initiative at Harvard University. His research has addressed cognitive and emotional development in children, with a special concern for the role of the temperament in personality and in understanding of the moral emotions. His most recent book is "The Long Shadow of Temperament" (2004, written with Nancy Snidman). Some ideas in this essay were drawn from a forthcoming book, "A Young Mind in a Growing Brain" (written with Norbert Herschkowitz), to be published next year.

(C) 2004 by the American Academy of Arts \& Sciences such a comparative posture here and describe seven psychological features that are either restricted to or enhanced in humans compared with our closest relatives, the chimpanzees. Four are of the first category; the other three are quantitative enhancements on chimpanzee talents.

The distinct psychological qualities of Homo sapiens are traceable to genetic changes that permitted the founder cells that become mature neurons to continue to divide for an extra seventy-two hours. Those additional cell divisions significantly expanded the size of the human cortex and contributed to the novel cognitive, emotional, and motor skills that emerge in humans over the course of development.

However, some scientists remain inexplicably resistant to acknowledging that any human quality is unique. When a linguist claims that only humans have a language with a grammar, a scientist will reply that chimpanzees can be taught to communicate with pieces of plastic. Jane Goodall's discovery that chimpanzees use tools is celebrated because of its implication that my use of a hammer to hang my granddaughter's recent artwork on the wall is not fundamentally different from a chimpanzee's use of a twig to ferret out termites. But the modern syn- 
thesis in evolutionary biology does not demand that every feature that belongs to a particular family, genus, or species has a homologous structure or function in a related taxon.

\section{Human and chimpanzee infants are} very similar to each other at the end of the first year. Both species locomote, attend to unexpected or unfamiliar events, and remember where an attractive object disappeared ten seconds earlier. However, only twenty-four months later, children have diverged permanently from their primate relatives because maturational changes in the brain, informed by experience, have permitted the development of four uniquely human qualities. Children now infer varied thoughts and feelings in others; use a symbolic language with a grammar and semantic categories for events that share no physical features (for example: milk, mother, and pink rabbits); understand the concepts of good, bad, right, and wrong, as well as experience a distinct feeling when they contemplate or violate an acquired prohibition; and become consciously aware of some of their intentions and feelings. ${ }^{1}$ I now consider these four functions in more detail.

\section{1}

The ability to infer the intentions, evaluations, and feelings of others is evident in an experiment where an adult hides a toy under one of three covers behind a barrier so that the child cannot see where the toy is hidden. If, after removing the barrier, the adult directs her gaze toward the toy's location, two-year-olds, but not one-year-olds, reach in the direc-

1 Jerome Kagan, The Second Year: The Emergence of Self-Awareness (Cambridge, Mass. : Harvard University Press, 1981). tion of the adult's gaze, indicating that they assume the adult is looking at the place where the toy rests. Such an inferential ability is necessary for feeling empathy with another. The two-year-old who hears her mother scream in pain as she catches her hand in a closing door associates the scream with her memory of past painful experiences, relates the latter to the perception of distress in the parent, and then announces with her face and posture an empathic concern for the victim. The child may even run to her mother to offer a reassuring embrace.

Although chimpanzees occasionally track the gaze of another animal and appear to be able to infer that another cannot see a piece of food hidden behind a barrier, they do not understand that another animal intends to share information with them. Chimpanzees watching a human adult perform simple actions with a tool and objects focus their attention on the objects rather than the adult's movements, because they fail to infer that the person's manipulations are guided by an intention and a plan. No pair of juvenile or adult chimps would throw a small ball back and forth between them, because they are incapable of appreciating that a partner intends to engage in a reciprocally cooperative act that has no implication for the gaining of food or protection. Every two-yearold child makes this simple assumption automatically.

Humans feel uncertain when they infer that another person might harbor undesirable thoughts about them; chimpanzees feel uncertain when they anticipate actions another animal might direct at them. Doubt over whether another will regard one as dumb, disloyal, or deviant is qualitatively different from doubt over whether another animal is about to attack, dominate, or seize a 
piece of fruit. A major event in human evolution was the replacement of a vigilant posture toward the potentially threatening actions of another with worry over the possible opinions of another.

\section{2}

Although apes can be taught, with considerable training, to treat pieces of plastic as symbolic of objects, no chimpanzee comes close to the linguistic ability of the average four-year-old who uses language to represent abstract ideas. One four-year-old, on noting that her dresses were closely packed in her closet, said to her mother, "My dresses are friends." The capacity to infer another's intention is exploited in the acquisition of language, for when a parent speaks to the child, the latter assumes the former intends to communicate information about the world. The acquisition of semantic networks permits the invention of symbolic similarities among very different physical events. Chimpanzees and children can detect a crescent shape shared by a slice of lemon and a new moon, but only the latter detect the symbolic features shared by a cookie, a smiling face, a pink sunset, and a curved geometric figure because of words that link these events in a semantic network for the concept 'pleasing.'

The psychologist Ellen Markman has suggested that children begin the learning of language with the advantage of three biologically based biases. ${ }^{2}$ The first is the assumption that when an adult speaks a word in the presence of an object, the word probably applies to the whole object. Two-year-olds hearing

\footnotetext{
2 Ellen Markman, "Constraints on Word Learning," in Megan R. Gunnar and Michael P. Maratsos, eds., Modularity and Constraints in Language and Cognition (Hillsdale, N.J. : L. Erlbaum Associates, 1992), 59-102.
}

their parent say "spider" as the latter points to an unfamiliar dark object on top of a sandpile assume that the word refers to the entire insect and not to its The uniquely human in human nature location, odd-looking appendages, or the sandpile. (The philosopher Willard van Orman Quine, who failed to acknowledge this bias, wondered what a visitor to a foreign land would conclude about the meaning of an unfamiliar word when he heard a native say "Gavagai" as a rabbit sprinted across the grass.)

A second bias is the assumption that a word probably refers to a category of similar objects, rather than to the specific entity that is perceived. A child who hears the parent say "Look at the squirrel" assumes that all objects with similar features have the same name. The third bias tempts young children to assume initially that each object has only one name. If three-year-olds hear an unfamiliar word (for example, 'goox') in the presence of both a cup and an unfamiliar object, they assume that the word must apply to the latter object. A student baby-sitter reported that our three-yearold daughter was puzzled when the student announced that she was planning to be a mother and a doctor. Fortunately, this third bias is tamed before children enter school.

The universal emergence of language in children with a healthy central nervous system exploits cognitive talents that serve other purposes. These talents include selective attention to adults, detection of low-level correlations between events, sensitivity to physically distinct sounds (for example, the sound 's' at the end of a word to represent the English plural), the assumption that adults speaking to them are trying to communicate information, and, finally, the ability to detect and invent similarities between the concepts that name events as different as a fly and a tree. 
Detection of consistency, as well as inconsistency, in the semantic networks that comprise a belief system is a salient human quality. It is not obvious why detection of inconsistency among one's semantic networks evokes a subtle but nonetheless uncomfortable feeling. Members of each language community have learned the transitional probabilities between words in narratives, as well as the differential strengths of associations between and among words. Most Americans expect the word 'ago' to follow 'years,' and respond with 'moon' when asked to report the first word they think of when they hear the word 'sun.' A violation of either probability elicits a distinct brain response and a feeling that psychologists call cognitive dissonance. This may be one reason why magicians in ancient Greece used unfamiliar combinations of words in their incantations. Use of the counterfactual in sentences ("If the sun were to die tomorrow ...") mutes the dissonance and allows the person to consider the possible consequences of a low-probability event. It is unlikely that chimpanzees imagine improbable events, although this claim requires more proof.

Some might argue that the uncertainty created by cognitive dissonance is an inherent property of the brain, analogous to the fact that dissonant musical chords produce an evoked potential in the cochlear nucleus that is distinctly different from that produced by consonant chords. The dissonant melodies provoke four-month-old infants to turn away, often with a facial expression of disgust. A second view is that the uncertainty is built on early experiences of seeing that an object cannot be simultaneously big and small, up and down, light and dark, or inside and outside a container. However, this account does not explain why statements that do not contain anto- nyms also create dissonance (for example, "dogs are vegetables"). No current explanation of this phenomenon is satisfying.

Nonetheless, poets take advantage of this property of mind, for they often use semantic inconsistency to surprise readers in order to achieve an aesthetic effect. Consider, for instance, the following word pairs from the first five lines of T. S. Eliot's poem "The Waste Land": April-cruellest; Lilacs-dead; Memorydesire; Dull-spring; Winter-warm. The final verse of Dylan Thomas's poem "If I Were Tickled by the Rub of Love" contains three perfect examples: Fear-apple; Bad-Spring; Thistle-kiss.

\section{3}

Although Enlightenment commentators nominated language as the feature that best separated humans from animals, the ancients thought that morality enjoyed that function. The author(s) of the tree of knowledge allegory in Genesis understood, long before Plato and Hume, that humans are distinguished by an obsessive concern with good and bad events and spend most of each day trying to gather evidence that affirms their membership in the former category.

Every human society has semantic concepts for the ideas of good, bad, right, and wrong, and most humans experience a changed feeling when they contemplate, or commit, a behavior that violates a standard they regard as proper. The anthropologist George Murdock once composed a list of sixty-seven features present in all cultures. Almost half of the features are ethical rules describing activities that ought or ought not to be displayed. "Know thyself" and "Nothing in excess," statements inscribed at the oracle in Delphi, are examples of two of the moral imperatives included in that list. 
The argument that moral standards derive from sensory pleasure and the reduction of pain cannot explain why people become angry when they see strangers violate standards they believe are morally proper. Such acts provoke observers to question the correctness of their moral commitments. Because these beliefs are central to each day's decisions, their violation, even by a stranger, threatens the rational foundation of each observer's conduct. No ape would show signs of anger upon seeing an unfamiliar animal take food from another, as long as the victim was not a genetic relative.

The primatologist Frans de Waal tries to persuade readers with anecdotes of chimpanzee behavior that these animals possess rules and punish those who break them. ${ }^{3}$ De Waal concedes, however, that he has never seen a guilty chimpanzee. It is unlikely he will ever see one, because guilt requires an agent to know that a voluntary act that could have been suppressed has hurt another. Guilt requires the ability to reflect on a past action that injured another in some way, to realize that the behavior could have been inhibited, and to appreciate that the self was the cause of the ethical violation. Guilt is not a possible state for chimpanzees.

The extensive semantic networks for the concepts of ethical propriety and impropriety have three branches. One refers to the actions that violate community standards for appropriate behaviors that presumably apply to everyone. A second entails the ethical obligations linked to the particular social categories to which one's self belongs (for example, most grandmothers believe they should be affectionate with their grandchildren). The third branch, which emerges

3 Frans de Waal, Good Natured (Cambridge, Mass. : Harvard University Press, 1996). by the seventh or eighth year, motivates humans to attain ideal forms. The ability to imagine the perfect parent, scientist, or friend requires a brain/mind that can generate cognitive representations of what might be possible. Apes and humans create representations of experiences that are psychological averages of actual encounters. But only humans possess conceptions of the most perfect form for a particular class of experiences.

Although an understanding of right and wrong and a feeling of uncertainty over violating moral standards are present by the third year, humans require an additional ten to twelve years before they will feel morally obligated to hold a consistent set of ethical beliefs. Adolescents, but not five-year-olds, wonder about their place in society, make plans for the future, and integrate memories of childhood with their current experience in order to understand their life circumstances.

\section{4}

An acute consciousness of one's feelings, intentions, and properties is a fourth unique quality of Homo sapiens. The term 'consciousness' probably does not name a unitary phenomenon, because the specific quality of consciousness, and its biological foundations, varies with the nature of the mental activity. Moment-to-moment changes in sensation that originate, for example, in the taste of chocolate or the smell of perfume, and which need not involve language, comprise one category. A special area of prefrontal cortex that receives sensory information represents one of the material bases for this form of consciousness, which we might call sensory awareness.

A second form, awareness of properties, is a consciousness of one's physical 
features, beliefs, talents, personality traits, moods, and social categories. The awareness of being politically conservative, Methodist, and shy, for example, requires activation of a part of the cortex different from the circuits activated by the awareness of a toothache. The awareness that one is about to implement or suppress an action, which requires still another brain circuit, is a third form of consciousness. The neuroscientist Michael Gazzaniga believes that a fourth form is the interpretation of one's feelings, perceptions, and actions through the construction of a coherent explanation of the state of consciousness at the moment.

Some might argue that even though these phenomena recruit different brain circuits, they share a common feature and therefore constitute a single process. For example, a common set of hand muscles is used to pick up a cup, brush one's teeth, or sign a check. Those who believe in multiple forms of consciousness would claim that because the profile of brain activity and the subjective state are distinct for each form, it is reasonable to reject the assertion of a single state of awareness. A consciousness of the smell of smoke from a bedroom, of a well-constructed argument, and of the finger movements while playing the piano are easily differentiated, both psychologically and neurobiologically.

Further, the four forms of consciousness may not have evolved at the same time, for they do not emerge simultaneously in the individual. The earliest signs of awareness of sensory events appear in the first year, before children are aware of their symbolic features. It is not until the second birthday that children smile following completion of a difficult task because they are aware of having attained a goal, or lower their head in embarrassment when they cannot repro- duce an adult action because they are aware of having violated an adult expectation. By the third birthday, children describe what they are doing as they are doing it because they are aware of their intentions. And by the fourth birthday, children regularly integrate the present moment with their recollections of the past and begin to impose the interpretations that Gazzaniga regards as an essential function of consciousness. Chimpanzees might be aware of the taste of particular fruits, and of the patterns of light and shadow on the forest floor, but it is unlikely they possess forms of consciousness beyond the sensory. No primatologist claims that apes reflect on their age or wonder whether they will be able to control the number of offspring they will bring into the world.

The combination of semantic networks, an appreciation of right and wrong, and conscious awareness of properties of self leads inevitably to categorizations of self that have strong evaluative connotations. All adolescents have learned semantic categories for their gender, family name, and developmental stage. Some add categories for their clan, caste, religion, or region of residence. More important, all are aware of the behaviors appropriate for each of these categories, and feel obligated to maintain semantic consistency between the features that define the category, on the one hand, and their thoughts and behaviors, on the other. Adolescent boys assume they should not wear girls' clothes even if they have never done so, have never been punished for such actions, nor have seen others criticized for this behavior.

The assignment of self to class, ethnic, national, and religious semantic categories has a profound influence on human emotions and behaviors. The writer Michael MacDonald, born to a very poor 
Boston family, remembers in a memoir feeling proud of his Irish heritage when his neighborhood resisted the judicial decision to bus school children from South Boston in the service of racial integration. Humans can feel shame, anxiety, or guilt if they think the community regards their family or any one of their social categories as possessing undesirable qualities. Many adults born to Holocaust victims after 1945 carry a burden of guilt or shame because of the horrible atrocities experienced by their parents. Many Americans felt a vicarious shame for their national category when they learned that American soldiers were destroying the homes of innocent Vietnamese.

The moral power of the self's social categories derives from the fact that the child's initial words are for observable objects and events that have stable, essential features. All objects called dogs should bark and have fur; if they do not, they are less than ideal dogs. Thus, when children learn the terms for social categories like 'girl,' 'boy,' 'Palestinian,' or 'Hispanic,' they are prepared to believe that these words, too, name a set of inherent psychological characteristics belonging to those in the category. Children feel obligated to be loyal to the features that define the categories to which they belong, and experience as much cognitive dissonance if they stray from those obligations as they would if they saw an animal without fur that never barked that was called a dog.

There are two types of social categories. Nominal categories, like gender and stage of development, have relatively fixed features and appear early in development. The ethical obligations attached to these categories are not linked to a specific other person and apply across a broad array of contexts. The second class of categories, acquired lat- er, is defined by a particular social relationship between the self and another, and includes the categories 'friend,' 'son,' 'daughter,' 'parent,' 'brother,' and 'sister.' The ethical obligations linked to these categories (usually loyalty, affection, honesty, and nurture) are attached to specific others. The social category 'friend,' for example, applies to a specific peer; hence, the obligations appropriate for one friend might differ from those appropriate for a different playmate. If a friend happens to be cautious much of the time, a child will feel obligated to dominate the dyad; but the same child may feel obliged to display deference to a different friend who likes to be dominating.

Egalitarian societies try to award greater significance to the ethical directives tied to relational categories because nominal ones imply differential status and privilege. In order to derive pride from a relational category, the individual must implement the obligatory actions. Egalitarian societies want their members to feel virtuous because of their achievements or benevolent behaviors toward others, not because they are members of a particular group.

Americans complain about the obvious increase in materialism in our society over the last half century. I suspect that one important reason for the obsession with accumulating clothes, cars, homes, and winter cruises is that the human moral sense requires knowing that some actions, and the symbolic prizes they may lead to, imply that one is more virtuous than another. Meanwhile, our society's desire to honor an egalitarian ethos requires a denial of special privilege to some categories that, in earlier centuries, were more automatic sources of virtue. Nineteenth-century white Christian males whose fathers and grandfathers attended college could 
reassure themselves of their virtue by simply reminding themselves of their membership in this quartet of categories. The ethic of egalitarianism, on the other hand, denies the prize of selfsatisfaction to any nominal category. Every American must attain his or her daily supply of virtue through personal accomplishments, through perfecting a talent, establishing a relationship, or acquiring status or wealth. Because gaining wealth, which most believe requires effort and talent, seems to be a possibility for most citizens, it has become a primary symbol of virtue in contemporary America. If a person cannot use gender, skin color, ethnicity, family pedigree, or occupation as a sign of worth, one of the few remaining symbols is the accumulation of property. No goal as glittering as equality of dignity can be had without a price.

Humans, in addition, display three abilities that are quantitative enhancements on chimpanzee talents, rather than unique characteristics: humans have a greater capacity to recall the past and imagine the future, to seek novelty, and to separate survival from inclusive fitness.

\section{5}

Although apes can remember the past and anticipate the future, humans expand both timelines to distant horizons. Sixty-year-olds can recall their first day at school and can anticipate what might occur two decades in the future when senility is imminent. There is no evidence, at least at present, that chimps sitting quietly on the forest floor can anticipate or recollect events several decades before or after the current moment.

Human adults who hear a seven digit telephone number for the first time can hold it in awareness for as long as thirty seconds in a process called working memory. Chimps possess a working memory, but its capacity is more limited.

The ability to manipulate several ideas simultaneously on the stage of working memory often leads to the detection of novel relations among mental structures or to an insight that reorganizes current understanding. Semantic networks were reshuffled when nineteenth-century readers of Darwin's Origin of Species began to entertain the notion that humans probably evolved from a primate ancestor. The automatic reshuffling of old assumptions permits one to avoid the uneasiness that follows recognition of a logical inconsistency in related beliefs.

\section{6}

The human attraction to new experiences also expands a primate competence. Chimpanzees seek new fruits to eat, new places to rest, and new mating partners, but humans spend more time than any other animal looking for unfamiliar events that can be comprehended and new skills that can be mastered. No other primate would risk survival, and a curtailment of reproductive fitness, by climbing Mount Everest, parachuting from a plane, or swimming across the English Channel.

The desire for and the ability to adapt to novel conditions is due, in part, to the structure of the human brain. The amygdala, a small, almond-shaped structure with several neuronal clusters tucked inside the temporal lobe, is an important site responsive to unexpected or unfamiliar events. When such experiences occur, excited neurons in the central nucleus of the amygdala send messages to bodily targets that lead to changes in heart rate and body posture. Over the millions of years of evolution from mouse to human, the central nucleus became smaller. As a result, humans are 
less likely than chimpanzees to become immobile or to experience a racing heart when they encounter an unfamiliar member of their species. When a mammalian species is domesticated, not only does the central nucleus become smaller, but the snout (nose, mouth, and mandible) becomes flatter because of the actions of genes that control the migration and final functions of a small necklace of cells, called the neural crest, that appears during the first six weeks following conception. The human face is considerably flatter than the face of a chimpanzee.

The suggestion that humans are domesticated apes may strike some readers as absurd, given the daily media announcements of murder, rape, and torture committed within our species. But these cruelties, although horrific, are statistically infrequent anomalies. If one could sit atop Mount Olympus and count the number of acts of kindness, nurture, honesty, cooperation, civility, and affection, as well as the number of hostile, rude, dishonest, aggressive, or violent behaviors that occurred across the world each day, the value of the former would always be larger than that of the latter - a fact that is not true for chimpanzees.

Still, the balance, even for human beings, may be shifting - not because our species is innately vicious, but rather because of the assumption, greatly reinforced in modern societies after the seventeenth century, that one should only pursue individual rather than collective goals.

\section{7}

This brings us to a final quality, admittedly more controversial, that distinguishes humans from apes. We are the only species that, during some historical eras, can dissociate survival to reproductive maturity from inclusive fitness. The biological concept of inclusive fitness, a relative property, is defined by the reproductive success of each agent and all her genetic relatives, compared with the success of a related strain or species in the same ecological setting.

Survival to reproductive maturity is usually positively correlated with inclusive fitness in every species. But the invention of inexpensive, effective contraceptives has allowed many human couples to limit the size of their family or, in some cases, to have no children at all. Increasing numbers of European, North American, and Japanese couples are restricting the size of their families in order to gain signs of virtue through personal accomplishment, education, enhanced social status, and new sensory delights. This decision is inconsistent with the biological demand to maximize inclusive fitness. The historical events of the past twenty thousand years created social conditions in economically developed societies that placed the almost conscious desire to regard oneself as virtuous in competition with the silent, unconscious biological urge for inclusive fitness.

The genome of contemporary humans is essentially the same as that of our founding ancestors. But the first modern humans, who appeared between one hundred and one hundred fifty thousand years ago in a warm ecology, and whose social organization consisted of foraging bands of thirty to fifty individuals, many of whom were genetically related, were cooperative with and loyal to their group. ${ }^{4}$ Successful adaptation demanded the suppression of excessive competition, selfishness, and selfaggrandizement.

Even though the first humans were perfectly capable of self-interest, un-

4 Peter Bogucki, The Origins of Human Society (Walden, Mass. : Blackwell, 1999). 
checked displays of this intention would have provoked rejection, exile, or, in some cases, murder. The gradual replacement of resource sharing and suppression of an exuberant celebration of the self with their opposites over the past twenty thousand years required a number of events, but, especially, the receding of the glaciers, which enabled the establishment of agriculture and the growth of cities; and, more recently, distant communication through books, radio, television, and the Internet; inexpensive and efficient forms of transportation and contraception; and the belief, partially a product of science, that an ethic demanding kindness, honesty, and loyalty to non-kin could not be defended, on biological grounds, as having an a priori validity.

In many parts of the industrialized world these events have created a social ambience characterized by geographical and psychological isolation from parents and siblings; awareness of the economic circumstances of millions of strangers in distant places; a larger status differential within and among populations and, therefore, greater uncertainty over one's relative status; decreased likelihood of punishment for disloyalty to one's primary groups; control of fertility; and the legal protection of infants, children, and the elderly with serious physical impediments. These characteristics are inconsistent with the original human tendency to place the vitality and potency of the group ahead of the psychological satisfactions of the individual.

Celebrated novelists, poets, and playwrights are able to articulate the dominant moods within their societies. Contemporary Western writers who enjoy the respect of discerning readers regularly depict loneliness, sadness, cynicism, and lack of loyalty to lover, spouse, child, employer, aging parent, or nation - com- pare Brontë with Bellow or Beckett. A short story in The New Yorker in 2003 describes a loving husband who, having reluctantly agreed to his wife's request to perform euthanasia because of her painful cancer, leaves her bedroom after the act, goes downstairs, and has sex with her best friend. The editors of the magazine would not have published this story if they thought their readers would have found it offensive. I suspect that the editors of a comparable publication in Beijing or Cairo would not have accepted this story.

Even though improved nutrition, potable water, efficient disposal of sewage, and modern medicine have permitted a longevity twice as long as the life span enjoyed by the foragers, survival is only one component of inclusive fitness; the number of healthy offspring is the more important feature. History exploited the competences of self-awareness and a moral sense to allow some humans to dissociate survival from inclusive fitness. Although Adam Smith believed that society would prosper if each individual pursued his own interests first, he was equally certain that each person's natural concern for the opinions of others would effectively restrain unbridled selfinterest. Smith could not have imagined, two hundred years after he wrote The Wealth of Nations, that large numbers of humans would live in cities with millions of strangers to whom they were indifferent. Few chimpanzees could survive under such conditions.

Most adults must bend their ethics a little to permit the behaviors that the shape of their social structure requires. If they resist, they can become vulnerable to corrosive tensions. A majority of North Americans and Europeans, and especially those who live and work in metropolitan areas, deal with strangers whom they suspect will lie, exploit them, 
block access at crowded intersections, and push ahead in long queues. Each individual must rationalize a ready access to anger in order to resist exploitation and to protect property and dignity. Television plays dramatize how easily rage can well up to force otherwise reasonable people to behave in ways they will regret, even though the characters are usually forgiven if their intentions were not irredeemably evil. In order to rationalize the blizzard of cruelty, greed, rudeness, and dishonesty, many have come to believe that it is not always possible, and probably not adaptive, to exert continuous control over anger, cupidity, rivalry, and jealousy. Belief in this rationalization mutes guilt and dilutes a sense of personal responsibility for harshly competitive attitudes that might hurt another. I suspect that the television series The Sopranos owes its popularity to the fact that most viewers will feel morally arrogant because they are less mean than the members of the Soprano family.

The belief that anger, self-interest, and competitiveness should not be suppressed because they are natural emotions has advantages in a society where a large number of strangers must compete for a small number of positions of dignity, status, and economic security. Under these conditions, it seems rational to be self-interested, and irrational to be too cooperative, too loyal, or too altruistic.

\begin{abstract}
A rash of books published over the last twenty years claims that unconflicted selfishness is to be expected given our evolutionary history. 5 After pointing to examples of self-interest in many animal species, these books imply that because this motive is present throughout na-
\end{abstract}

5 David P. Barash, Whisperings Within (London: Penguin, 1979). ture, humans need not feel ashamed of their narcissism. However, anyone with a modest knowledge of animal behavior and minimal inferential skill could find examples of animal behavior that support almost any ethical message. Those who wish to sanctify marriage can point to the pair-bonding of gibbons; those who think infidelity is more natural can nominate chimpanzees. If one believes that people are naturally sociable, cite baboons; if one thinks humans are solitary, focus on orangutans. If one wants mothers to care for their infants, rhesus monkeys are the model; if one prefers the father to be the primary caretaker, point to titi monkeys. If one is certain that men should dominate harems of beautiful women, cite elephant seals; if one believes women should be in positions of dominance, describe elephants. Nature has enough diversity to fit almost any ethical taste.

Humans are selfish and generous, aloof and empathic, hateful and loving, dishonest and honest, disloyal and loyal, cruel and kind, arrogant and humble; but most feel a little guilt over an excessive display of the first member of each of these seven pairs. This feeling is uncomfortable, and we are eager to have it ameliorated. Confession or psychotherapy is effective for some, and it is likely that many adults feel better when they read that their less social urges are natural consequences of their phylogenetic history. The currently high status of the biological sciences has made it possible for students of evolution to serve as therapists to the community.

The psychological differences between the first humans and contemporary members of our species are sufficiently dramatic to motivate a curiosity over whether the current motive hierarchy of the latter group is a biologically prepared propensity that has a natural 
priority, or one demanded by the special conditions history has created.

Most young monkeys in natural settings play with other monkeys. But rhesus monkey infants that have been taken from their mother early in life and placed with an inanimate wire object will sit crouched in a corner of a cage away from their peers. ${ }^{6}$ The capacity to crouch alone in a corner is inherent in the rhesus monkey genome, but actualization of that profile requires very unusual and unnatural conditions. Thus, it is relevant to wonder whether the current prevalence of unconflicted selfinterest in many industrialized societies, like the rhesus monkey's solitary crouched posture, must overcome a biologically stronger urge to be a loyal, cooperative, and trusting member of a stable group that provides protection from external threat.

Most species that violate their salient natural propensities risk a loss in inclusive fitness. A warning may be hiding in this biological fact.

6 Harry F. Harlow and Margaret K. Harlow, "Social Deprivation in Monkeys," Scientific American 207 (1962): 136-146. 
This article has been cited by:

1. Astrid Hopfensitz, Ernesto Reuben. 2009. The Importance of Emotions for the Effectiveness of Social Punishment. The Economic Journal 119:540, 1534-1559. [CrossRef]

2. Stephen Loughnan, Nick Haslam. 2007. Animals and Androids: Implicit Associations Between Social Categories and Nonhumans. Psychological Science 18:2, 116-121. [CrossRef]

3. Nick Haslam. 2006. Dehumanization: An Integrative Review. Personality and Social Psychology Review 10:3, 252-264. [CrossRef]

4. Paul G. Bain, Yoshihisa Kashima, Nick Haslam. 2006. Conceptual beliefs about human values and their implications: Human nature beliefs predict value importance, value trade-offs, and responses to value-laden rhetoric. Journal of Personality and Social Psychology 91:2, 351-367. [CrossRef]

5. Nick Haslam, Paul Bain, Lauren Douge, Max Lee, Brock Bastian. 2005. More human than you: Attributing humanness to self and others. Journal of Personality and Social Psychology 89:6, 937-950. [CrossRef] 